\title{
Demographic profiling of poisoning in Emergency Department of Kathmandu Medical College - A cross sectional study
}

\section{Kushwahah A', Singh PK²}

${ }^{1}$ Anu Kushwaha, Lecturer; Department of Emergency; Kathmandu Medical College Teaching Hospital, Sinamangal, Kathmandu, ${ }^{2}$ Pankaj Kumar Singh, Department of Forensic Medicine; Kathmandu University School of Medical Sciences, Dhulikhel.

\begin{abstract}
Background: Poisoning is a very common medico-social problem in our part of the world. It significantly contributes to the morbidity and mortality, which is a big concern and burden to our society.

Objective: To determine the demographic profiling of poisoning in Emergency Department of Kathmandu Medical College.

Methododogy: This is a cross sectional study conducted for the period of six months from March 2017 to September 2017 at the Emergency Department Kathmandu medical college teaching hospital. The study includes the cases of poisoning brought to the above mentioned institute for management. The data thus collected was entered in the SPSS and analysed to find the poisoning profile. Ethical clearance was taken from Institutional Review Board of Kathmandu Medical College.

Results: A total of 40 cases of poisoning came to Emergency Department over the period of six months of which 14 (35\%) were males and 26 (65\%) were females. The mean ages for males were 32.07 years and females were 26.23 years. Regarding time of consumption $42.5 \%$ of cases consumed poison at night. The most common poison consumed was Organophosphorus (55\%) and next in kin was paracetamol (15\%). However, type of Organophosphorus could not ascertained due to lack of information from the patent party.

Conclusion: People in the productive age groups are more prone to poisoning with various products due to stress or other social economic factors. Social education and strict rules and regulation for the sale of the pesticides can be useful in containing this problem.
\end{abstract}

Key words: Pattern; Pesticides; Poisoning.

\section{INTRODUCTION}

Doison is any substance which if introduced in the living body by any route can cause ill health or death'. The manner of poisoning can be different depending upon the case; however it can be broadly classified in suicidal, accidental and homicidal. Suicidal poisoning accounts to a majority of cases brought to the Emergency Department ${ }^{2}$. Poisoning either suicidal or accidental has been a major public health problem in our part of the world. Although there are various educational programmers, social campaigns to address

Address for correspondence

Dr. Anu Kushwaha

Lecturer; Department of Emergency

Kathmandu Medical College Teaching Hospital

Sinamangal, Kathmandu.

E-mail-anukushwaha@gmail.com the problem of poisoning in our society, it is still a bulk of medical emergencies in our population. The pattern of incidence of poisoning and the risk factors associated with it is varying in population to geographical areas. According to the World Health Organization (WHO) more than 800,000 deaths occur due to poisoning annually ${ }^{2}$.

WHO has reported that the majority of cases of poisoning were due to pesticide use, especially the developing countries $^{2}$. Nepal as developing country, agriculture is a dominated profession, the use of pesticides is very common and so is poisoning due to it. Though there are laws to prohibit its sale over the counter, implementation of these laws lack the social construct. Identifying the pattern of poisoning and risk factor can be beneficial for our society by reducing morbidity and mortality associated with poisoning ${ }^{3 .}$ The factors 
responsible for poisoning are impulsive response to economic problem or psychological stressful events like illiteracy, frustration, familial disharmony, love tragedy, exam failures and poor revolution for the acceptability to the poison ${ }^{4}$. The objective of the present study is to find out the pattern of the poisoning in Kathmandu.

\section{METHODOLOGY}

This is a cross sectional hospital based study conducted in the department of Emergency, Kathmandu Medical College and Teaching Hospital during the period from March 2017 to September 2017. The patients brought to emergency with the history of poisoning were included in this study. The ethical clearance was obtained from Institutional Research Committee of Kathmandu Medical College. Verbal consent was taken from the patient or patient party for the study.

The demography such as types of poisoning, manner of poisoning, age and sex of the survivor were recorded and documented. The type of poisoning was determined by history given by patient or patient party, clinical features, and stuff material presented by patient or relatives. The exclusion criteria were drugs reaction and food poisoning. The data thus collected was entered in Microsoft Excel and was analyzed using SPSS statistical package version 16. Descriptive statistics was used to analyze the data.

\section{RESULTS}

This study comprised of a total of 40 patients brought to Emergency Department over a period of six months with acute poisoning. Of the 40 patients, 14 (35\%) were male and 26 (65\%) were female of Nepalese origin. The age distribution for male ranged from 19 to 74 years with the mean age of 32.07 years and for female the age ranged from 8 to 66 years with the mean age of 26.23 years as described in table 1.

Majority of cases of acute poisoning that were brought for treatment were married $(57.5 \%)$, and $42.5 \%$ were unmarried. Of married patents $43.5 \%$ were male and $56.6 \%$ were female, similarly $23.5 \%$ were male and $76.5 \%$ were female of the unmarried sample. About $42.5 \%$ of cases consumed poison at night of which $76.5 \%$ were female, the highest in comparison to other time of the day, $20 \%$ of cases consumed poison during morning of which $62.5 \%$ were female, $20 \%$ of cases consumed in the evening of $50 \%$ were female, lastly $17.5 \%$ of cases consumed at afternoon of $57.1 \%$ were female.

The most common poisoning was of Organophosphorus compounds which accounted to 55.0\%. The second most common poisoning was Paracetamol overdosing which is a unique finding. Following Paracetamol, which accounted for $15 \%$ of the total cases, Aluminum Phosphide and Alcohol derivatives were at $7.5 \%$ each, and carbolic acid (harpic) at $5.0 \%$ of all cases all of which are described in table 2.

Coming to the manner of consumption of poison, the most common manner was suicidal with $87.5 \%$ and $12.5 \%$ cases were accidental consumption of poison. During the period of this study no cases of homicidal poisoning was brought to Emergency department of Kathmandu Medical College.

Table 1: Age distribution of patient according to sex

\begin{tabular}{cccccc}
\hline Gender & N(40) & $\begin{array}{c}\text { Minimum } \\
\text { (Years) }\end{array}$ & $\begin{array}{c}\text { Maximum } \\
\text { (Years) }\end{array}$ & $\begin{array}{c}\text { Mean } \\
\text { (Years) }\end{array}$ & SD \\
Male & 14 & 19 & 74 & 32.07 & 13.11 \\
Female & 26 & 8 & 66 & 26.23 & 13.92 \\
\hline
\end{tabular}

N: Number of cases; SD: Standard deviation

Table 2: Poisoning pattern in this study

\begin{tabular}{lccc}
\hline Poison & Frequency & Percentage & Cumulative Percent \\
OP \& derivatives & 22 & 55.0 & 55.0 \\
\hline Paracetamol & 6 & 15.0 & 70.0 \\
Other Drugs & 4 & 10.0 & 80.0 \\
Aluminium Phosphide & 3 & 7.5 & 87.5 \\
Alcohol \& derivatives & 3 & 7.5 & 95.0 \\
Carbolic acid & 2 & 5.0 & 100.0 \\
\hline
\end{tabular}

OP: Organophosphorus. 


\section{DISCUSSION}

Poisoning is a problem worldwide and consumes not only immense health resources but also causes morbidity and mortality. The outcome depends on the nature, duration, severity \& toxicity and availability of health services as well ${ }^{4,5}$. In our study female(65\%) were more affected than the male (35\%) population which was quite similar to that result of Howlader Mar et al and Prasant Gupta et al ${ }^{5,6}$. Female male ratio is 1.8:1 in our study which is similar to other studies done in tertiary care centre in Northern India ${ }^{6,7}$. The age group of 25 to 35 years was most commonly involved in the poisoning. $57.5 \%$ patients were married and $42.5 \%$ were married. The study carried out by Rashid Husain et al from Bangladesh and Hemani Ahuja et al had the similar type of result ${ }^{7,8}$. This age group is most active in family, professional and social life resulting in devastating outcome in the society.

Vijay Mate from south India observed that Organophosphorus poisoning constitute the maximum number of patients. Pesticide poisoning caused $66.6 \%$ death in studies carried out in Bangladesh ${ }^{8,9}$. Our study showed that Organophosphorus poisoning was the first cause (55\%) while paracetamol poisoning $15 \%$ was the second cause which indicated the similarity in the other study. Suicidal manner (87.5\%) of poisoning is more common than the accidental and homicidal pattern in our study and the result are similar to the other stud ${ }^{1,9,10}$. Family disputes, unemployment problem and stress in the profession may be the contributing factors for committing suicide for both male and female.

\section{CONCLUSION}

Our study indicated that younger age groups of productive life affected by poisoning is great lost to the country. Strict regulations for availability of such pesticides, community education, and uplift of socioeconomic condition of population and lastly availability of better health care to all section of society will alleviate problems of poisoning.

\section{REFERENCES}

1. Panda BB, Hansda MK, Mishra K, Samantsinghar P. Study of Poisoning Cases in an Indian Tertiary Care Teaching Hospital. 2015;37(2):165-8.[FullText]

2. Chataut J, Adhikari RK, Sinha NP, Marahatta SB. Pattern of Organophosphorus Poisoning: A Retrospective Community Based Study. Kathmandu Univ Med J. 2011;34(2):31-4.[PubMed]

3. Tsalikidis A, Vaos G, Gardikis S, Kambouri K, Tripsianis G, Mantadakis E et al. Acute Poisoning Among Children Admitted To A Regional University Hospital In Northern Greece. Cent Eur J Public Health. 2010;18(4):219-23.

4. Wickramasinghe $K$, Steele $P$, Dawson $A$, Dharmaratne D, Gunawardena A, Senarathna L et al. Cost of government health-care services in treating acute self-poisonings in rural district in Sri Lanka. Bull World Health Organ. 2009;87:180-5.[PubMed]

5. Howlader MAR, Sardar MH, Amin MR, Morshed MG, Islam MS, Uddin MZ et al. Clinico-epidemiological Pattern of poisoning in Tertiary Level Hospital. J Dhaka Med Coll. 2008; 17(2):111-15.[FullText]

6. Gupta P, Kumar A, Singh SP, Prakash M, Gupta M, Kumar $P$. Pattern of cases of acute poisoning in a rural tertiary care center in northern India. National Journal of Community Medicine. 2016;7(4):307-10. [FullText]

7. Ahuja H, Mathai AS, Pannu A, Arora R. Acute poisonings admitted to a tertiary level intensive care unit in northern India: Patient profile and outcomes. Journal of Clinical and Diagnostic Research. 2015;9(10):1-4.[PubMed]

8. Hossain R, Amin R, Hossain AR, Kahhar A, Chowdhury FR. Clinico-Epidemiological study of poisoning in a tertiary care hospital in Bangladesh. Journal of Emergency Practice and Trauma. 2017;3(1):4-10. [DOI]

9. Mate V. A Prospective Observational Study on Pattern, Severity and Outcome of Different Poisoning Cases in a Tertiary Care Hospital, India. Journal of Basic and Clinical Pharmacology. 2017;8(3):154-7.[FullText]

10. Maheswari E, Abraham L, Chacko CS, Saraswathy GR, Ramesh AC. Assessment of Pattern, Severity and Outcome of Poisoning in Emergency Care Unit. Journal of Applied Pharmaceutical Science. 2016;6(12):178-83.[FullText] 